\title{
Wind environment in the Lee of Kauai Island, Hawaii during trade wind conditions: weather setting for the Helios Mishap
}

\author{
John N. Porter • Duane Stevens • Kevin Roe • \\ Sheldon Kono • David Kress • Eric Lau
}

Received: 6 February 2006 / Accepted: 17 December 2006 / Published online: 13 February 2007 (C) Springer Science+Business Media, B.V. 2007

\begin{abstract}
On 26 June 2003 (approximately 1030 local time) the Helios ultralight aircraft broke apart off the west coast of Kauai Island, Hawaii as it was climbing out of the Kauai wind shadow. Following the aircraft mishap, a study was carried out to understand the conditions on the day of the crash and to better characterize the wind in the lee of Kauai. As part of this effort, both aircraft measurements and numerical modelling studies were carried out. Measurements and models showed the trade wind flow was enhanced around the island creating a region of wind shear surrounding the leeside calm zone. This wind shear region was found to be vertically oriented along the south side but tilted northward with height along the northern side of the calm zone. Several other factors on the day of the crash were investigated including water vapour gradients, diurnal Island heating, and gravity waves but their possible influences on the crash could not be confirmed. While the numerical model captured the general
\end{abstract}

J. N. Porter $(\varangle)$. D. Stevens

School of Ocean and Earth Science and Technology,

University of Hawaii,

Honolulu, HI 96822, USA

e-mail: johnport@hawaii.edu

K. Roe

Maui High Performance Computing Center,

Kihea, HI, USA

S. Kono

Statech International,

Honolulu, HI, USA

D. Kress

Island Air,

Honolulu, HI, USA

E. Lau

National Weather Service,

Eureka, CA, USA 
features of the Kauai leeside winds, the orientation of the calm zone was north of the observed one.

Keywords Hawaii - Helios aircraft - Island wake · Marine boundary layer · Trade winds . Wind turbulence

\section{Introduction}

The remotely controlled Helios aircraft was an innovative ultralight Uninhabited Aerial Vehicle (UAV) flying wing (developed by AeroVironment, Inc.) designed for high-altitude, long-duration flight (see Fig. 1). The Helios aircraft had already flown to altitudes of $29.5 \mathrm{~km}$ setting a new world record for non-rocket flight. The propeller-driven aircraft used solar panels during the day and was being tested for hydrogen fuel cells for nighttime power. The Helios aircraft is a prototype and further information is available at http://www.dfrc.nasa.gov/Education/Educator/Workshops/Hawaii/index.html.

On 26 June 2003, the Helios aircraft broke apart at approximately 1036 local time during a flight based out of the U.S. Navy's Pacific Missile Range Facility on the Hawaiian island of Kauai. The cause of the mishap was ascribed to the inability to predict the aircraft's increased sensitivity to atmospheric turbulence following the first time addition of fuel cells (Noll et al. 2004). In order to better understand the weather conditions during the Helios mishap a meteorological study was carried out as part of the NASA investigation. This involved numerical models, satellite image analysis, and several flights using light aircraft. Parts of these studies are reported here. While the Helios report uncovered deficiencies in the modelling of the Helios aircraft structure, the meteorological study found important weaknesses in current capabilities to provide information on turbulence fields.

The Kauai topography (see Fig. 2) consists of a mountain region located near the centre of the island with a maximum elevation of $1589 \mathrm{~m}$. In the crosswind direction the mountains provide a 27.5, 18.5, and $6.5 \mathrm{~km}$ obstruction at 660,1000 , and $1380 \mathrm{~m}$ elevation. Rather than being a smooth cone-pyramid shaped obstruction, the Kauai mountains are a complex assortment of deep canyons, ravines and ridges that extend

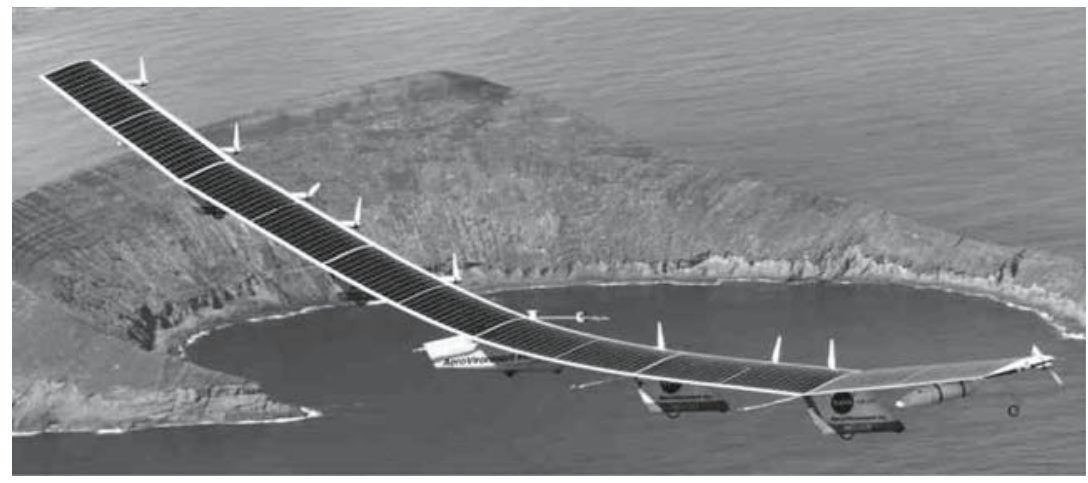

Fig. 1 Image of Helios aircraft prior to the mishap 


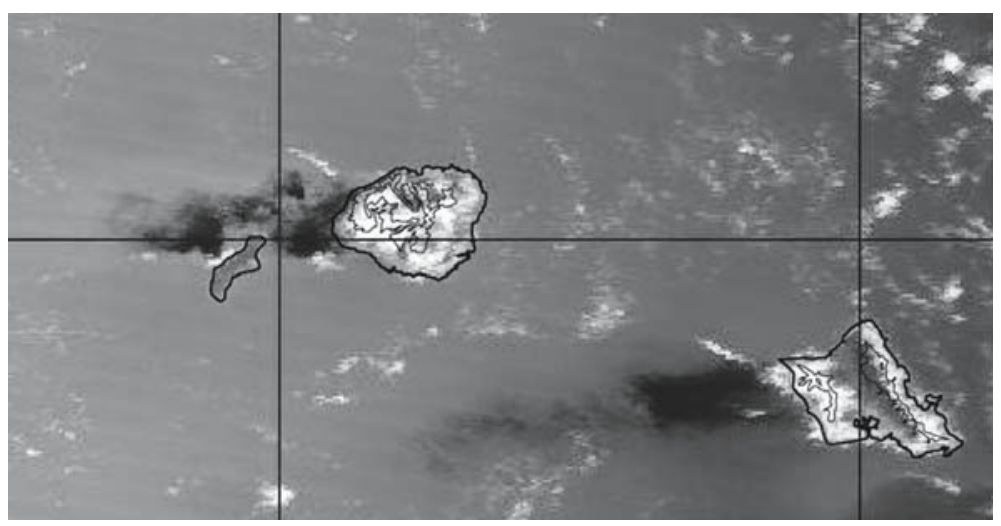

Fig. 2 Modis image showing calm zone behind Kauai and topography

deep into the system. Near the centre of the mountain range is the Waialeale swamp with one of the largest annual rainfall rates in the world (Ramage and Schroeder 1999). The blocking effect of the Hawaiian island mountains often produces wind and cloud perturbations that can persist for long distances (Hafner and Xie 2003). Close in the leeside of the islands it is common to find counterrotating eddies with calm or light westerly winds between them (Smith and Grubisic 1993). Depending on the location of the sun glint, this calm zone can appear in satellite images due to changes in surface roughness (Cox and Munk 1955). Figure 2 shows a MODIS (Moderate Resolution Imaging Spectroradiometer) image with the calm wind zone in the lee of Kauai on a typical trade wind day. Isoheights are used to give the island elevations.

The Froude number (wind speed divided by the Brunt-Vaisala frequency times the mountain height) is often used to characterize island blocking effects. For the Hawaiian islands the Froude number typically ranges from 0.2 to 0.5 (Yang and Chen 2006). Studies of obstructions with similar length and width (Smolarkiewicz and Rotunno 1989) demonstrated that as the Froude number decreases below 0.5 both leeside eddies (with counter flow behind the obstruction) and upwind blocking occur without surface friction effects being included in the model. Subsequent studies showed that when the length (along wind distance) of the obstruction increases then the leeside vorticies and the upwind blocking disappear (for a Froude number of 0.33) (Smolarkiewicz and Rotunno 1989). Thermal heating and cooling of the islands also plays a role in the strength of the west side sea breeze throughout the day (Leopold 1949).

\section{Meteorological conditions on 26 June 2003}

The Helios plane broke apart on a fairly common trade wind summer day in Hawaii. Figure 3 shows the large-scale wind fields for this day based on MM5 simulations at 54$\mathrm{km}$ resolution. The Hawaiian Islands were located within the trade wind belt, which on this day extended from approximately $25^{\circ} \mathrm{N}$ to the intertropical convergence zone (approximately $5^{\circ} \mathrm{N}$ ). Two late season mid-latitude storms were occurring well north of the islands. West of the islands (near the dateline) the east-north-easterly trade winds merged into a synoptic-scale shear line along the southern extent of a cold front. 


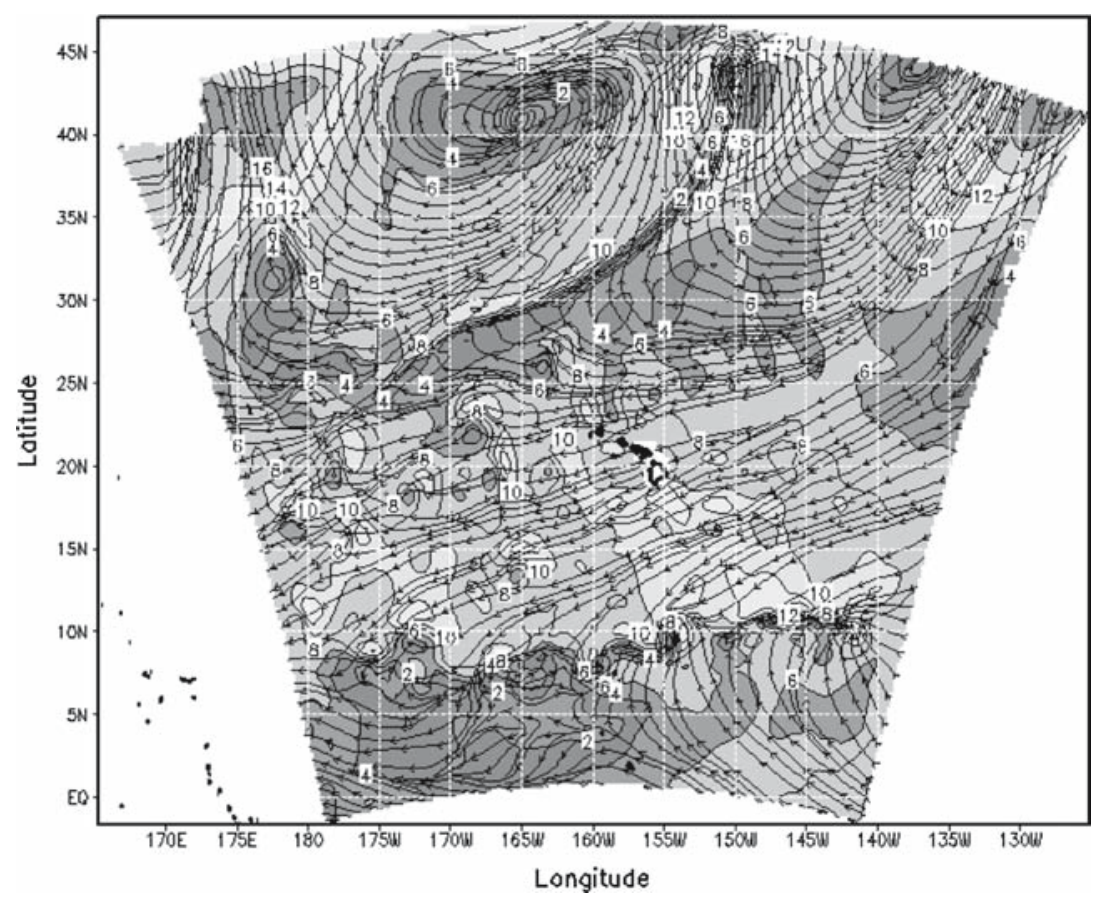

Fig. 31000 hPa MM5 large-scale wind field on 26 June 2003 (1000 Hawaii time). The winds are shown as arrows and regions of constant wind speeds (isotachs in $\mathrm{m} \mathrm{s}^{-1}$ ) are shaded differently

The model winds on 26 June 2003 (Fig. 3) can be compared with the climatological mean winds for June (Fig. 4) (Sadler et al. 1987). The model wind speeds near Hawaii on the day of the accident $\left(6-8 \mathrm{~m} \mathrm{~s}^{-1}\right)$ were slightly larger than the climatological values (approximately $6 \mathrm{~m} \mathrm{~s}^{-1}$ ) and contained more small-scale features that would be smoothed out in climatological analysis. The wind directions near Hawaii on 26 June 2003 and in the June climatology are approximately the same (east-north-east) with the exception of the more easterly trade winds near the northern side of the islands near Kauai. In agreement with the model winds, Donahue (2003) tracked cloud motions in satellite images on the day of the Helios mishap and found that the cloud level winds over Kauai were easterly. "The more southerly direction of the trade winds", on 26 June 2003, was also noted by the flight team as part of their pre-flight weather assessment (Noll et al. 2004).

In terms of synoptic-scale processes, the centre of the anticyclone, north of Hawaii, is further north $\left(45^{\circ} \mathrm{N}\right)$ on 26 June 2003 , than the climatological value $\left(30^{\circ} \mathrm{N}\right)$ but the pressure ridge north of Hawaii occurs at about the same latitude $\left(30^{\circ} \mathrm{N}\right)$. In the climatology the pressure ridge $\left(30^{\circ} \mathrm{N}\right)$ extends well to the west but on 26 June 2003 , this gives way to a front/shear line at approximately $163^{\circ}$ east. Overall the main exception to the climatology is the presence of two mid-latitude storms well north of the islands.

On 26 June 2003 a weak upper level trough was present over Hawaii with westsouth-west winds and maximum winds of 15.5-26 $\mathrm{m} \mathrm{s}^{-1}$ occurring between 125 and $250 \mathrm{hPa}$ pressure levels (see the Lihue sounding, Fig. 5). These features reflect the presence of a weak upper level trough that is common at this time (Sadler 1967). 


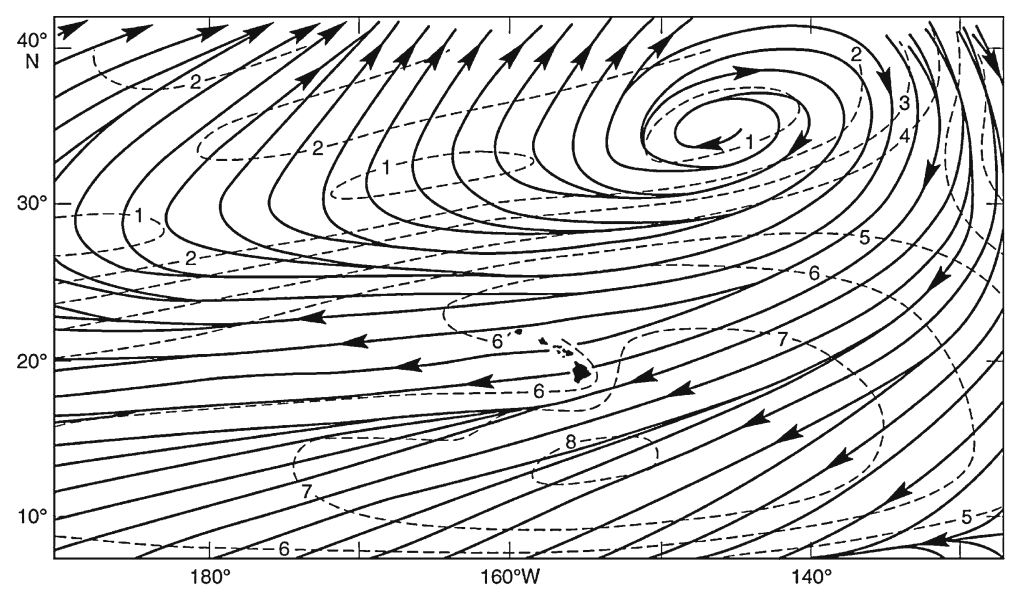

Fig. 4 30-year average June winds over Hawaii (from Sadler et al. 1987). Streamlines are displayed as solid lines with arrows; isotachs $\left(\mathrm{m} \mathrm{s}^{-1}\right)$ are dashed

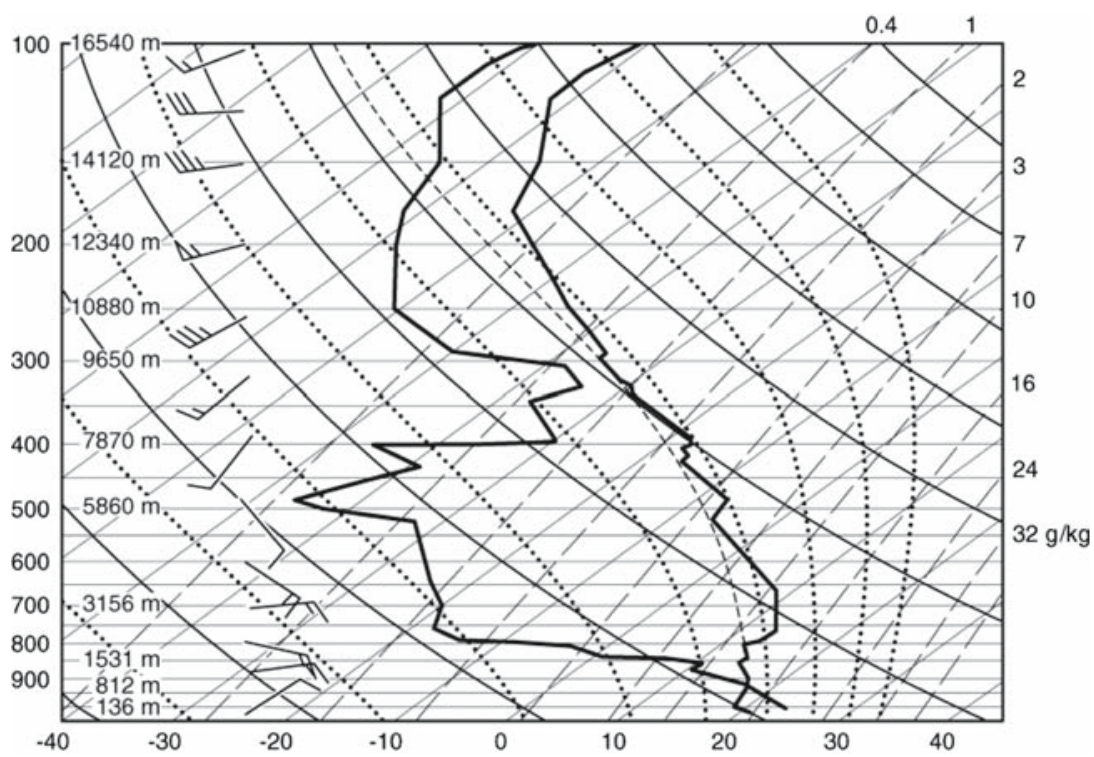

Fig. 5 Lihue, Kauai sounding at 0200 local time, plotted on a standard skew T - log p diagram. Temperature is on the right, dew point temperature on the left

Climatologically the tropical upper tropospheric trough (TUTT) is found just north of Hawaii (approximately $27^{\circ} \mathrm{N}$ ) during June and directly over Hawaii during July (Sadler 1975). Strengthening of the TUTT can cause enhanced summertime trade wind showers (known as wet trades) over the island mountains but generally trade wind showers remain light throughout the summer.

The Lihue soundings for 26 June 2003 (0200 local time) before the Helios mishap (at 1036), is shown in Fig. 5. Below $800 \mathrm{hPa}$ the winds were roughly east-north-east. These winds are in rough agreement with the synoptic wind conditions shown in Figure 
3 with the exception that the low-level winds (below $950 \mathrm{hPa}$ ) are more northerly. This is likely due to wind deflection by the Kauai mountains at the radiosonde site (Lihue airport on the south-east side of the island). The Froude number for this sounding is 0.22 , which falls within the low Froude number range expected for the Hawaiian Islands (Yang and Chen 2003). The base of the trade wind inversion is at $850 \mathrm{hPa}$ (approximately $1500 \mathrm{~m}$ ) at 0200 and rises to $800 \mathrm{hPa}$ (approximately $2020 \mathrm{~m}$ ) by the time of the 1400 sounding (not shown). The mixed-layer depth also grows during the day from $640 \mathrm{~m}$ (at 0200) to $1000 \mathrm{~m}$ (at 1400). Although it is possible that island heating affects the boundary-layer and mixed-layer depths, very rapid changes (on a one-hour time scale) in mixed-layer depth have been observed for open ocean trade wind conditions (Porter et al. 2003).

A separate synoptic feature, which can cause enhanced turbulence, concerns gravity waves (Hopkins 1977). Mountain induced gravity waves are quite common and have been seen on numerous occasions near Hawaii (Rogers et al. 1993; Dave Chen, pers. comm. 2005). Teets and Salazar (1999) report on a gravity wave encountered in the lee of Kauai (at approximately $3000 \mathrm{~m}$ height) during a Pathfinder flight on 9 June 1997. The gravity wave was attributed to Kauai mountain blocking and produced a gradual ascent and descent in the Pathfinder altitude (the Pathfinder was a precursor to the Helios aircraft). While the vertical motion was very clear in the Pathfinder data it was not obvious in radiosonde observations, which were taken just before and after the flight. In other unpublished observations, gravity waves have been observed in processed satellite images of integrated water vapour (similar to Fig. 7) on the north-west leeside of Kauai on a day when gravity waves were visible from many of the Hawaiian Islands. No island-related gravity waves could be seen on the day of the crash (Figs. 6, 7 discussed below).

Cold fronts are also known to generate gravity waves (Fritts and Nastrom 1992). Based on satellite imagery from geostationary satellites gravity waves can occasionally be seen emanating from rapidly advancing cold fronts north of Hawaii (personal observations, and Hawaii National Weather Service communication). Figure 3 shows that at the time of the Helios mishap, two regions associated with a cold front existed north of Hawaii with winds directed towards Hawaii $\left(43^{\circ} \mathrm{N}, 130^{\circ} \mathrm{W}\right.$ and a weaker system at $43^{\circ} \mathrm{N}, 153^{\circ} \mathrm{W}$ ). The satellite images did not show clear evidence of gravity waves and therefore it is difficult to know if long range gravity waves were of importance to the Helios mishap.

The Helios flight on the day of the mishap was later than usual raising the possibility that surface heating could have increased convective thermal activity downwind of Kauai. The Lihue nighttime (0200 local time) sounding on the day of the Helios mishap (Fig. 5) has a surface temperature of $24^{\circ} \mathrm{C}$ and rising parcels would have been capped by the trade wind inversion at approximately $1500 \mathrm{~m}$ height. On the same day the afternoon sounding (1400 local time) had a surface temperature of $29^{\circ} \mathrm{C}$ at the surface and $25^{\circ} \mathrm{C}$ just slightly above the surface. Assuming the largest surface temperatures and no entrainment, it was possible that low-level thermals may have been able to break through the trade wind inversion at the time of the 1400 sounding. This significant surface heating is the likely cause of cloud growth and development that occurred over much of Kauai later in the day, as seen by satellite (Donahue 2003). An increase in thermal activity at the time of the Helios flight (approximately 1030) is possible but difficult to assess.

Just prior (0955) and after (1122) the Helios flight, two radiosondes were released from the Kauai Pacific Missile Range Facility (where the Helios aircraft was launched 


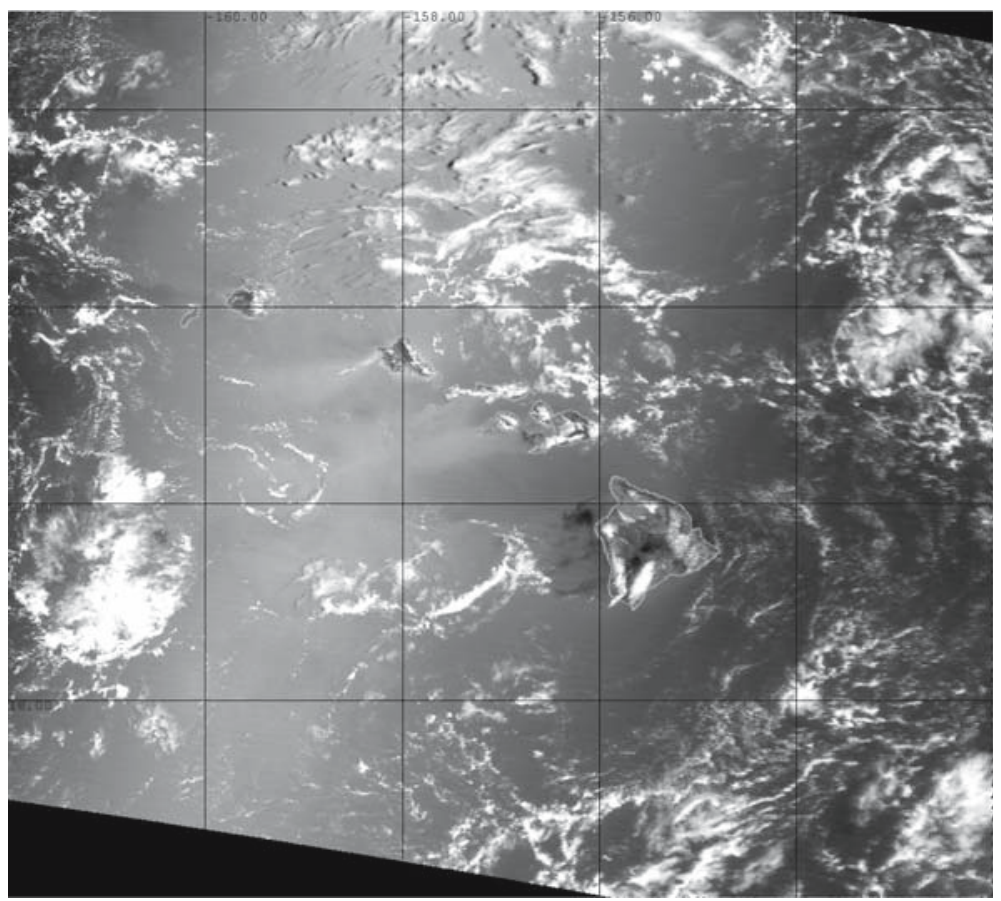

Fig. 6 MODIS visible image (250 m resolution) collected on 26 June 2003 at 1122 Hawaii time. The major islands, from west to east, are Kauai, Oahu, Maui, and the Big Island of Hawaii

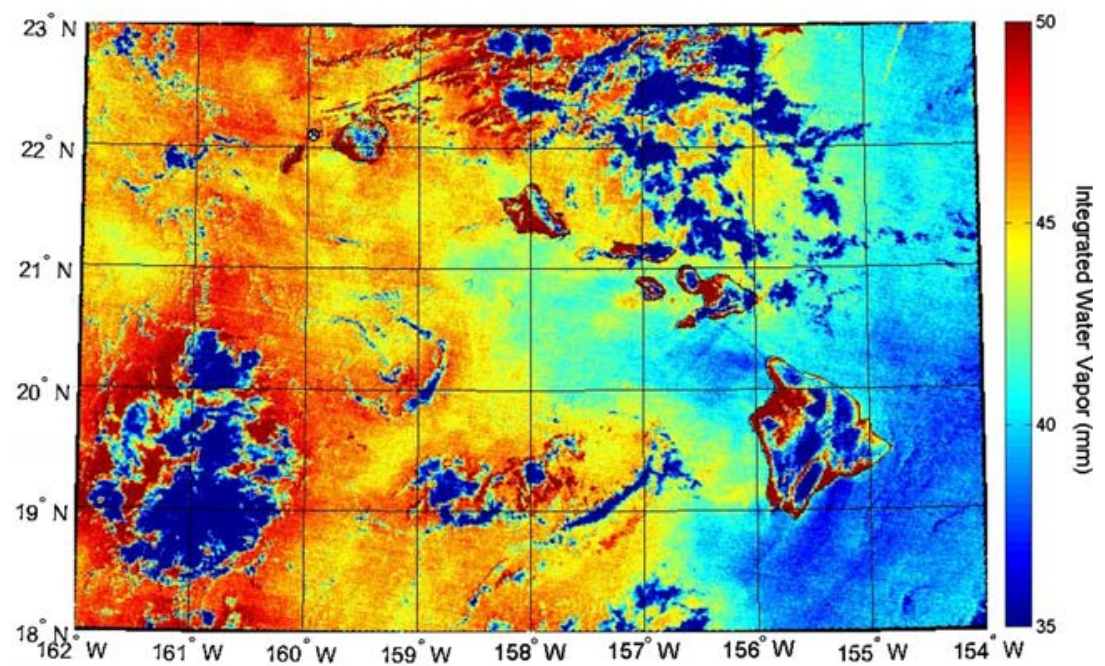

Fig. 7 Same image as Figure 5 processed to obtain integrated water vapour. Integrated water vapour is observed above the surface or above cloud top. The major islands, from west to east, are Kauai, Oahu, Maui, and the Big Island of Hawaii

on the leeside of Kauai) (Donahue 2003). GPS sensors on the radiosondes showed light and variable $0-3 \mathrm{~m} \mathrm{~s}^{-1}$ sea-breeze winds below $915 \mathrm{~m}$ with slightly increasing onshore (westerly) winds by the afternoon sounding. From 0915-1525 m height the 
radiosondes measured a region of vertical wind shear with winds increasing from 1 to $5-6 \mathrm{~m} \mathrm{~s}^{-1}$ with height. The Helios aircraft also measured GPS winds until its mishap occurred. Similar to the radiosondes, it experienced light and variable winds below $840 \mathrm{~m}$ then encountered a region of stronger vertical wind shear (from 1 to $6.2 \mathrm{~m} \mathrm{~s}^{-1}$ ) while climbing from 840 to $915 \mathrm{~m}$ height. It is within this wind shear region where the Helios mishap occurred.

Figure 6 is a MODIS satellite image (collected by the Hawaii NASA Direct Broadcast MODIS facility) taken at 1122 local time, approximately $1 \mathrm{~h}$ after the Helios mishap. The image shows relatively cloud free conditions over the Hawaiian Islands (suitable for the Helios solar powered aircraft). The image contains a large region of sun glint running from the north to the south and passing over the Kauai-Oahu area. Regions of enhanced and diminished sun glint can highlight sectors with different wind speed such as often occurs in the lee of islands (Smith and Grubisic 1993; Smith et al. 1997). In Fig. 5 the orientation of the leeside sun glint suggests the winds were from about $070^{\circ}$ for most of the islands, in agreement with the synoptic winds shown in Fig. 2. The one exception is Kauai region, where more easterly winds are inferred (approximately $95^{\circ}$ ) (seen west of Kauai and north-west of Niihau). This is consistent with the results of the large-scale modelled winds (Fig. 3).

Figure 7 shows the vertically integrated water vapour derived from the same MODIS image (Fig. 6) using the split window technique, which has been tested for AVHRR images (Motell et al. 2002) over Hawaii, but not validated for MODIS images. Although the integrated water vapour values shown in Fig. 7 appears somewhat large, the relative spatial scales are not affected by the currently unknown offset factor. The obvious feature is the dramatic east-west gradient in integrated water vapour as well as smaller cloud-scale gradients. Comparing the 1400 radiosonde profiles for Lihue and Hilo, both had similar moist layer depths but the Hilo mixed-layer was significantly dryer than at Lihue in agreement with the east-west gradient seen in the integrated water vapour image. The integrated water vapour image also shows a cloudy area in the lower left (south-west) portion of the image, which is embedded in a region of enhanced integrated water vapour. Based on GOES (Geostationary Operational Environmental Satellites) satellite imagery this is a region of dissipating convective activity that formed late the previous day and was the source of the cirrus over the Kauai Pacific Missile Range Facility in the early morning of 26 June 2003.

The cause of the east-west gradient in the integrated water vapour (Fig. 7) is unexpected for what appears to be steady trade wind flow conditions. In order to investigate this feature further, Lagrangian back trajectories were calculated for air terminating at various points in the moist and dry regions. These trajectories were obtained using the HY-SPLIT model (Hybrid Single Particle Lagrangian Trajectory) developed by Draxler and Hess (1998). Figure 8 shows trajectories ending near Hilo (within the region of lower integrated water vapour), and the western side of the Hawaiian Islands (within regions of larger integrated water vapour). All trajectories were for $200 \mathrm{~h}$ duration ending at 500-m altitude at 1400 local time 26 June 2003 (the time of the afternoon sounding). Since the trajectory paths were fairly similar, this cannot explain the moisture gradient seen in Fig. 7. Figure 8 also shows the altitude of the trajectories. The trajectories ending in the regions with higher integrated water vapour experienced more time in the surface mixed layer while the back trajectory ending in the drier area did not descend to $750 \mathrm{~m}$ (average top of the mixed layer, Porter et al. 2003) until just before arriving in Hawaii. This, and other trajectory tests that were carried out, were consistent with the idea that the regions of larger integrated water 

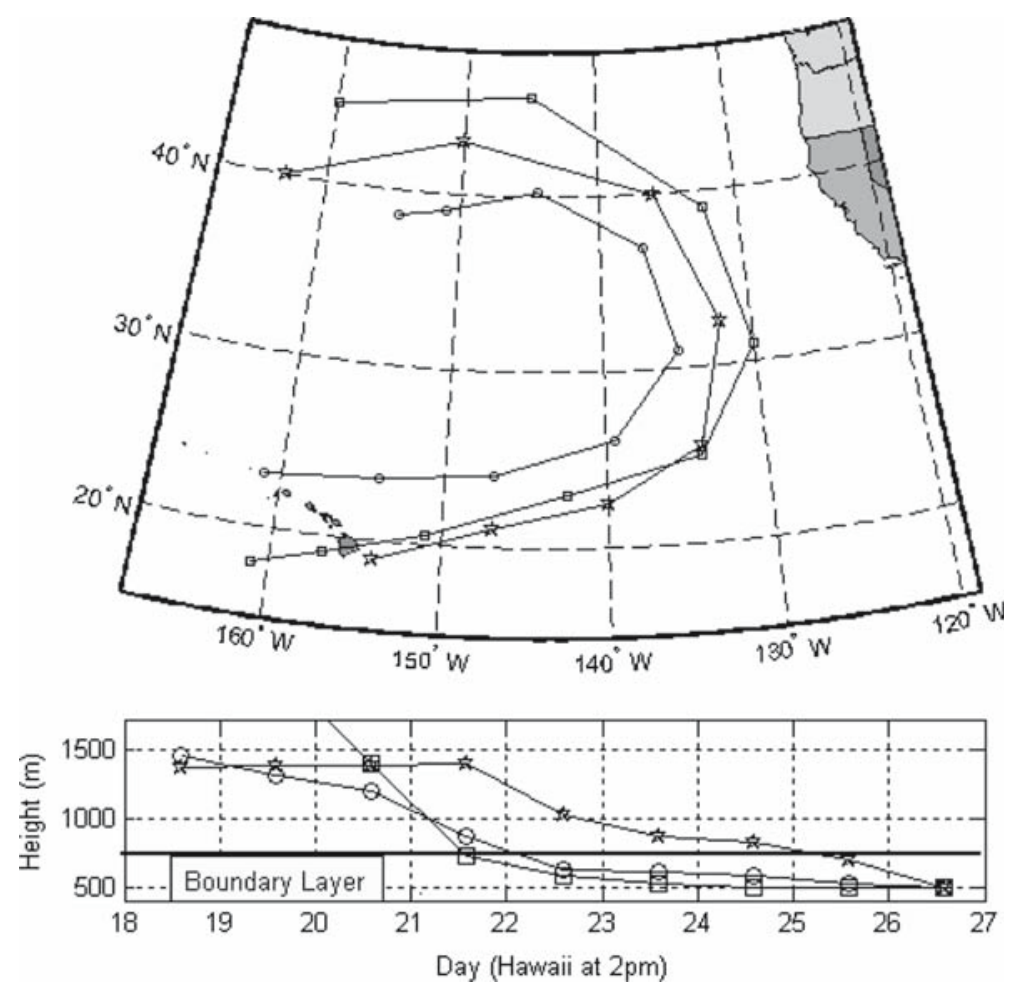

Fig. 8 Back trajectories showing position and height for trajectories that ended at $500 \mathrm{~m}$ height and in moist regions (circles and boxes) and in a relatively dry region (star)

were produced by the air spending more time within the surface mixed-layer where ocean evaporation moistens the air. Based on unpublished satellite observations we have observed that convective clouds near Hawaii are often associated with regions of larger integrated water. Gradients in integrated water are known to enhance convection along dryline regions over land (Hane and Ziegler 1993). This possibility has not been investigated over the ocean. Therefore it is possible that the gradient seen in Figure 7 had lead to enhanced convection near the gradient region but this could not be confirmed at this time.

\section{MM5 modelling}

In order to investigate the mesoscale conditions in the lee of Kauai on 26 June 2003, the fifth generation Mesoscale Model (MM5) of the Penn State / National Center for Atmospheric Research was run for the period from 24 June 2003 (1400 Hawaii time) to 27 June 2003 (1400 Hawaii time), at various resolutions down to both 1-km and $2-\mathrm{km}$ horizontal grid spacing. For initial and boundary conditions, large-scale analyses from the Global Forecast System (GFS) from the National Weather Service's National Centers for Environmental Prediction (NWS/NCEP), were utilized every $6 \mathrm{~h}$ throughout the 72 -h period. For this study one-way nesting was used (each larger grid influences the imbedded small-scale grid, but not vice versa) with four model resolutions, and with each grid interval decreasing in both horizontal directions by 
a factor of 3. Each nested domain contained 103 grid points in the two horizontal directions. Two sets of runs with differing vertical resolution were used: first with 26 layers and then with 52 layers. Only the 52 layer resolution cases are reported here. As is natural, the fields for the largest grid were relaxed toward the NWS/NCEP Global Forecast System (GFS) analysis near the outer boundaries, while each nested grid was matched to the next larger grid. The physical and dynamic parameterizations included: (1) surface thermodynamic fluxes, (2) predicted surface temperature (not specified);

(3) surface characteristics obtained from the NCAR data base (essentially consisting of a single vegetation type over land in Hawaii); (4) a dynamic radiative boundary condition applied at the upper model level; (5) Goddard Space Flight Center (GSFC) explicit moisture scheme with graupel; (6) the Grell cumulus parameterization scheme used for domains with grid size no less than $9 \mathrm{~km}$ (for small sized grids, no cumulus parameterization is used); (7) the Medium Range Forecast (MRF) planetary boundary layer algorithm; and (8) the "RRTM" (Rapid and Accurate Radiative Transfer Model) atmospheric radiation scheme. Several runs with the shallow cumulus convection option were carried out, but they are not reported here because of the NCAR MM5 group's caveats regarding their accuracy. All results presented here do not use the shallow cumulus convection option.

Figure 9 shows the model wind fields around Kauai for the $900 \mathrm{hPa}$ level, the approximate altitude of the Helios mishap $(915 \mathrm{~m})$. The obvious feature is the calm region in the lee of Kauai with winds less than $5 \mathrm{~m} \mathrm{~s}^{-1}$. The abrupt change in wind speed north and south of the calm zone defines two shear-line regions surrounding the island's calm zone shadow. Here we define an island scale shear line as a region of strong horizontal gradient of wind speed, which is often reflected at the surface in a change in sea state.

The angular orientation of the model calm zone (290 degrees) is slightly more northerly than that inferred (275 degrees) from the satellite images (Figs. 6, 7). This slight difference in angular orientation of the calm zone is possibly due to errors in the large-scale wind fields used for model initialization.

Figure 10 displays a vertical cross-section (aligned north-south) of the winds for the longitude where Helios mishap occurred (shown as circle-x symbol) and for the same model results as shown in Fig. 9. Stronger winds can be seen north, south, and above the calm zone, essentially surrounding the calm zone. The shear line region south of the calm zone has a vertical orientation. North of the calm zone the shear line is split into two regions with the lower one roughly over the surface shear line and the upper one tilted northward with height. At the surface the calm zone is approximately $17.5 \mathrm{~km}$ wide. Above $850 \mathrm{hPa}$ (approximately $1500 \mathrm{~m}$ ) the horizontal wind shear weakens and then disappears by $800 \mathrm{hPa}$ (approximately $2000 \mathrm{~m}$ ).

In order to test the robustness of these results, a different model run was carried out with a lower 2-km grid resolution. A simpler wind speed structure was observed with only a hint of a double minimum around $900 \mathrm{hPa}$. These differences between the model runs at $1-\mathrm{km}$ and $2-\mathrm{km}$ resolutions indicate that the wind structure is not necessarily fully resolved at $1-2 \mathrm{~km}$ model grids.

\section{Aircraft measurements on the Leeside of Kauai}

In order to obtain in situ turbulence measurements in the lee of Kauai, aircraft observations were carried out during August-October 2003. A twin engine Piper Navaho 


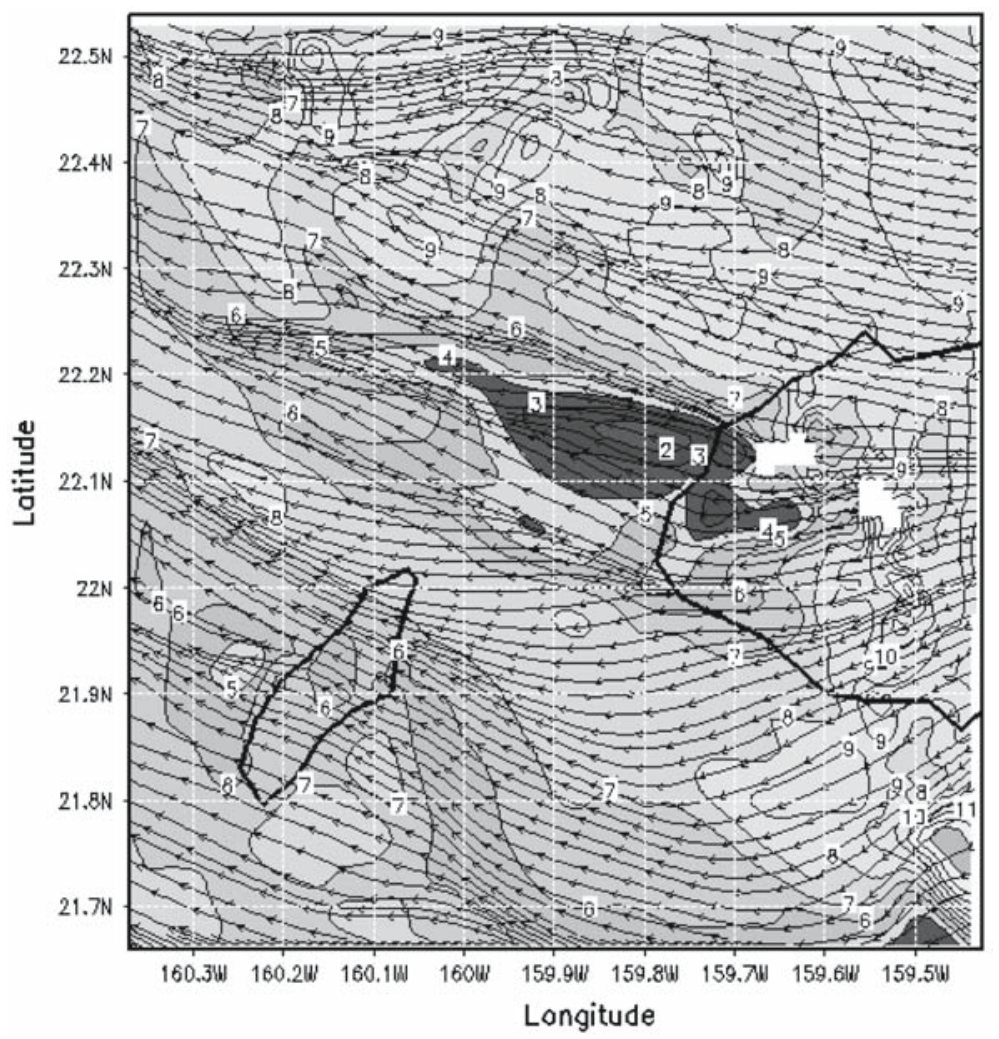

Fig. 9 MM5 model results (1-km resolution) $900 \mathrm{hPa}$ on 26 June 2003 at 1100 Hawaii time. The winds are shown as arrows and regions of constant wind speeds (isotachs in $\mathrm{m} \mathrm{s}^{-1}$ ) are shaded different

aircraft was employed to measure ambient temperature, ambient relative humidity, aircraft acceleration in all three directions and GPS position. Only measurements based on aircraft acceleration and GPS position are described here. All measurements were carried out at $4.5 \mathrm{~Hz}$ with the exception of GPS, which was recorded at $1 \mathrm{~Hz}$. Computer times were synchronized so that the GPS and the logged data could be combined in post processing. Data were collected with an Agilent 34970A datalogger at 5.5-digit resolution.

Flights were made on six days with some days including two flights. Table 1 gives the dates, times, average surface wind conditions and inversion height (from the Lihue sounding at 1400 local time) for each flight. Comments are given on some flights. Each flight began on Oahu and included a ferry flight from Oahu to Kauai (approximately 45 minutes time each way). Once over the leeside of Kauai, the typical flight plan included a series of north-south legs at different altitudes. These legs allowed us to measure the turbulence over the calm zones, the shear lines and regions north of the northern shear line (NSL) and south of the southern shear line (SSL).

On each leg of the crosswind flights the location of the surface shear line (transition from calm to rough water) was recorded by the pilot (a trained meteorologist). Combined with the GPS position it was possible to determine the location of the surface shear lines for each flight. The width of the calm zones between the NSL and SSL 


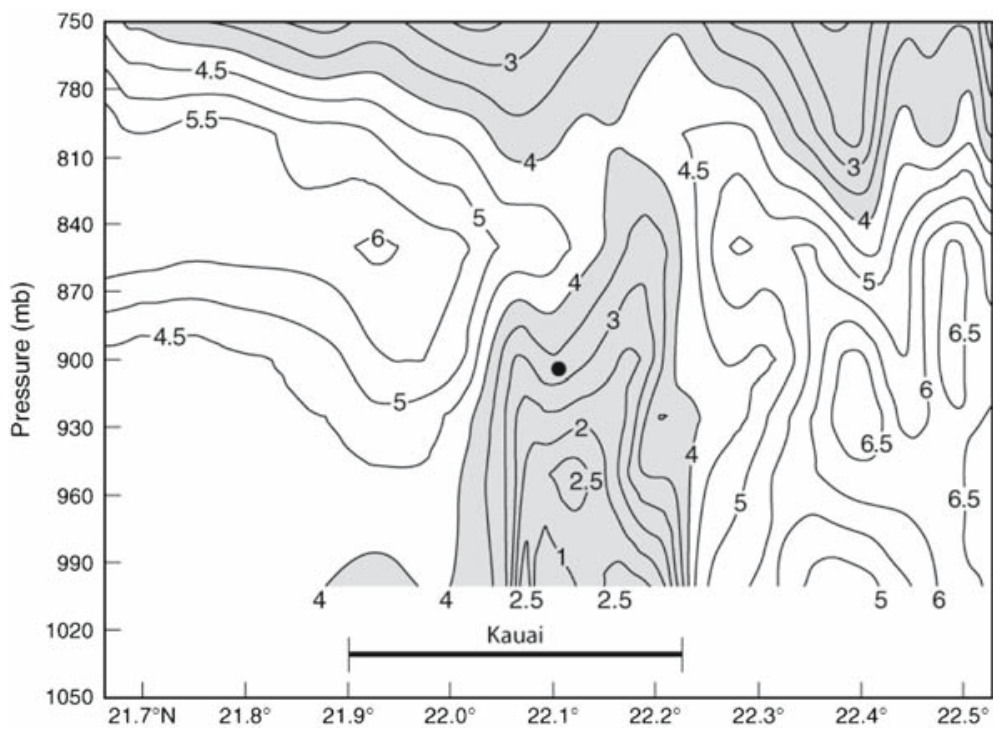

Fig. 10 MM5 (1-km resolution): cross section at $159.95^{\circ} \mathrm{W}$ of wind speeds (isotachs, $\mathrm{m} \mathrm{s}^{-1}$ ). The dark circle marks the location of the Helios mishap

Table 1 Dates of aircraft Flights, the times measurements were made west of Kauai, and the wind conditions and inversion heights and strengths of the 1400 Lihue sounding

\begin{tabular}{|c|c|c|c|c|c|c|}
\hline Flight & Date & $\begin{array}{l}\text { Local time } \\
\text { (hour) }\end{array}$ & $\begin{array}{l}\text { Wind } \\
\text { speed } \\
\left(\mathrm{m} \mathrm{s}^{-1}\right)\end{array}$ & $\begin{array}{l}\text { Wind } \\
\text { direction } \\
\text { (degrees) }\end{array}$ & $\begin{array}{l}\text { Inversion } \\
\text { strength, } \\
\text { height (m) }\end{array}$ & Comments \\
\hline$\# 1$ & $27 / 8 / 2003$ & $1000-1112$ & $7-10$ & $60-70$ & Strong, 2430 & \\
\hline \#2 & $30 / 8 / 2003$ & $1142-1300$ & $8-10$ & $100-120$ & Weak, 3900 & $\begin{array}{l}\text { Cloud Trail Formed } \\
\text { Over Calm Zone }\end{array}$ \\
\hline \#3 & $8 / 9 / 2003$ & $1000-1100$ & $8-10$ & $80-90$ & Strong, 2200 & \\
\hline \#4 & $13 / 9 / 2003$ & $1000-1100$ & $5-8$ & $70-100$ & Weak, 3260 & Wide Calm Zone \\
\hline$\# 5 \mathrm{a}$ & $10 / 10 / 2003$ & 0818-0918 & $7-11$ & $90-105$ & Strong, 2400 & Power Supply Failed \\
\hline$\# 5 \mathrm{~b}$ & $10 / 10 / 2003$ & $1030-1100$ & $7-11$ & $90-105$ & Strong, 2400 & Power Supply Failed \\
\hline$\# 6 \mathrm{a}$ & $13 / 10 / 2003$ & 0900-0936 & $7-10$ & $50-80$ & 1600 & $\begin{array}{l}\text { Weaker \& Higher } \\
\text { Inversion at } 0200\end{array}$ \\
\hline$\# 6 \mathrm{~b}$ & $13 / 10 / 2003$ & 1100-1136 & $7-10$ & $50-80$ & 1600 & $\begin{array}{l}\text { Weaker \& Higher } \\
\text { Inversion at } 0200\end{array}$ \\
\hline
\end{tabular}

varied from flight to flight and with time on a given day. As expected, the orientation of the shear lines varied from west-north-west to south-west as the trade winds varied from east-south-east to north-east. The pilot also noticed differences in the gradient of surface roughness as well as the abruptness of the shear line wind changes. On some occasions the white caps built up gradually over some distance, and on other occasions a large change occurred over a short distance. On days when the observed surface roughness gradient was strong, the exact location of the shear line was very easy to see. The pilot also noticed that the shear lines were not always straight lines but could be wavy, discontinuous and non-stationary. 


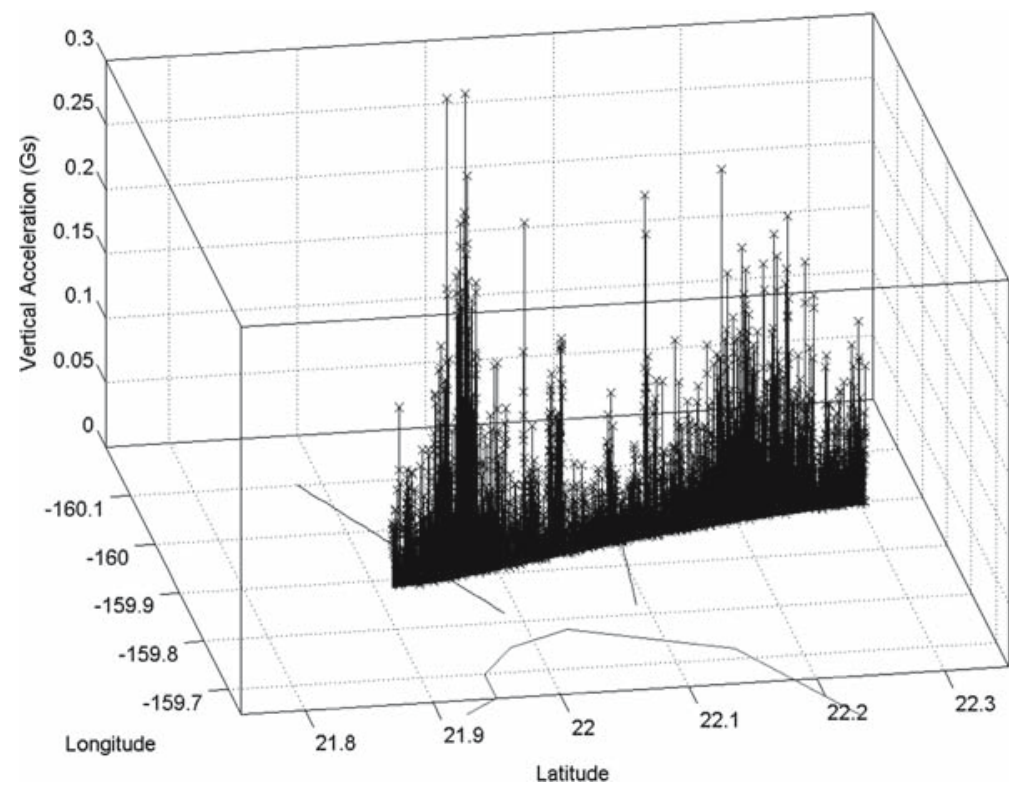

Fig. 11 Absolute values of aircraft vertical acceleration while passing along one leg of flight 3 at $920 \mathrm{~m}$ altitude

Aircraft acceleration was measured with a three-axis accelerometer. Only the vertical accelerations, assumed to be a measure of boundary-layer turbulence, are discussed here. Due to power supply problems in the latter flights the acceleration measurements have uncertainty of $25 \%$. The absolute value of the aircraft vertical accelerations for one leg of Flight 3 (at $920 \mathrm{~m}$ height) is shown in Fig. 11. The approximate locations of the surface shear lines are also shown as lines at the surface. In this example the turbulence is larger over the SSL while a wider area of moderate turbulence exists well to the north of the surface NSL.

As the overall orientation of the shear line varied with background trade wind direction, it is not appropriate to plot the turbulence fields simply as a function of latitude. In order to obtain a better representation of the calm zone the aircraft turbulence was plotted relative to distance from the centre of the calm zone. Furthermore, the distance from the centre of the calm zone to the measurement location is scaled by the ratio of the width of the calm zone on the day of the measurement divided by the average width of the calm zone for all the flights. This approach allowed for a composite of the turbulence fields for flights 2, 3, 4, and 6 (flights 1 and 5 experienced data problems). The composites were created by using the maximum acceleration magnitudes occurring in 10-s time intervals. The extent of the surface calm zone was obtained from pilot observations as the end of the surface calm zone. The accuracy of the positioning of the surface shear lines (transition from calm zone to wind roughened areas) was reduced when the aircraft was at higher altitudes but this uncertainty is expected to be less than $\pm 100 \mathrm{~m}$.

In carrying out this composite several steps were carried out. First the average distance between the northern and southern shear lines (as observed by the pilot) was calculated for all the flights and found to be $16.9 \mathrm{~km}$ with a standard deviation of 
$2.5 \mathrm{~km}$. Next, the location of the centre of the calm zone (midway between northern and southern shear lines) was determined for each flight. Then the distance from this centre point was calculated for each measurement. This distance was then multiplied by the ratio of the average width of the calm zone divided by the width of the calm zone on the day of the measurement. Therefore in the final composite the positions are scaled so that the shear lines occur at the same relative position on the graph.

Figure 12 shows the turbulence composite at four different heights in the lee of Kauai. Individual data points are given as well as a weighted average of the data (solid line). The most obvious features are the regions of maximum turbulence, which generally occurred over the surface shear line (shown as two straight lines in the Figures). Near the surface the regions of more intense turbulence are relatively broad but have a maximum centered over the surface shear lines. The next two heights, $450-600 \mathrm{~m}$ and 700-1000 m, show a significant increase in turbulence over the surface shear lines. Although the maximum turbulent intensities occurred over the surface shear lines, somewhat larger values also appear well north of the northern surface shear line. This pattern is in agreement with the model results (Fig. 10), which showed the northern shear line tilted northward and the southern shear line with no vertical tilt. Significant turbulence is also seen within the "calm zone" with the largest values near the top of the calm zone coincident with the larger wind shear there.

During flight 6 two legs were flown at the same height and approximately the same location. Each leg had different distributions of aircraft acceleration confirming that the location and time of the turbulent eddies were variable. Therefore the measurements shown in Fig. 12 should be considered as a limited set of measurements providing only a coarse understanding of the turbulence fields. In order to obtain a more definitive distribution of turbulence in the lee of Kauai many more flights would be needed to obtain better statistics.

Efforts to estimate the wind speed and direction were also carried out as part of the flights. During the experiment the pilots flew each leg at fixed headings and the aircraft position (with GPS) and plane relative speed (with our pitot tube) was recorded. The aircraft speed derived from our pitot tube and the standard aircraft pitot tube were compared on numerous occasions and found to be within $3 \%$ when the plane was flying level legs. In order to fly straight legs the pilots used a gyro, which was set to a magnetic compass at the beginning of each leg. Due to the electric fields created in the aircraft, the magnetic compass was found to be unreliable. This was later confirmed with a flux gate compass and tests along the aircraft runway. Therefore the legs were flown along straight legs but the heading of each leg was not certain. In order to obtain a rough idea of the heading for each leg, initial headings were calculated from the aircraft position. If the ambient winds were zero, these headings would correspond to the actual plane heading. Next the heading of each leg was slowly adjusted knowing that the large-scale winds were expected to be approximately from the east-northeast (from the Lihue sounding and numerical models). It was found that only a limited range of headings were possible that resulted in reasonable ambient wind speeds and directions along the north side of Kauai (compared to the Lihue soundings and the synoptic-scale weather charts). Once the aircraft heading was determined it was possible to derive winds from the aircraft motion and speed. While the wind speeds and directions derived in this way may have a bias error for each leg, the location of the changes in wind speed and direction is expected to be correct. The composite winds fields can therefore provide information on regions of relative stronger and weaker wind speeds and changes in wind direction. 

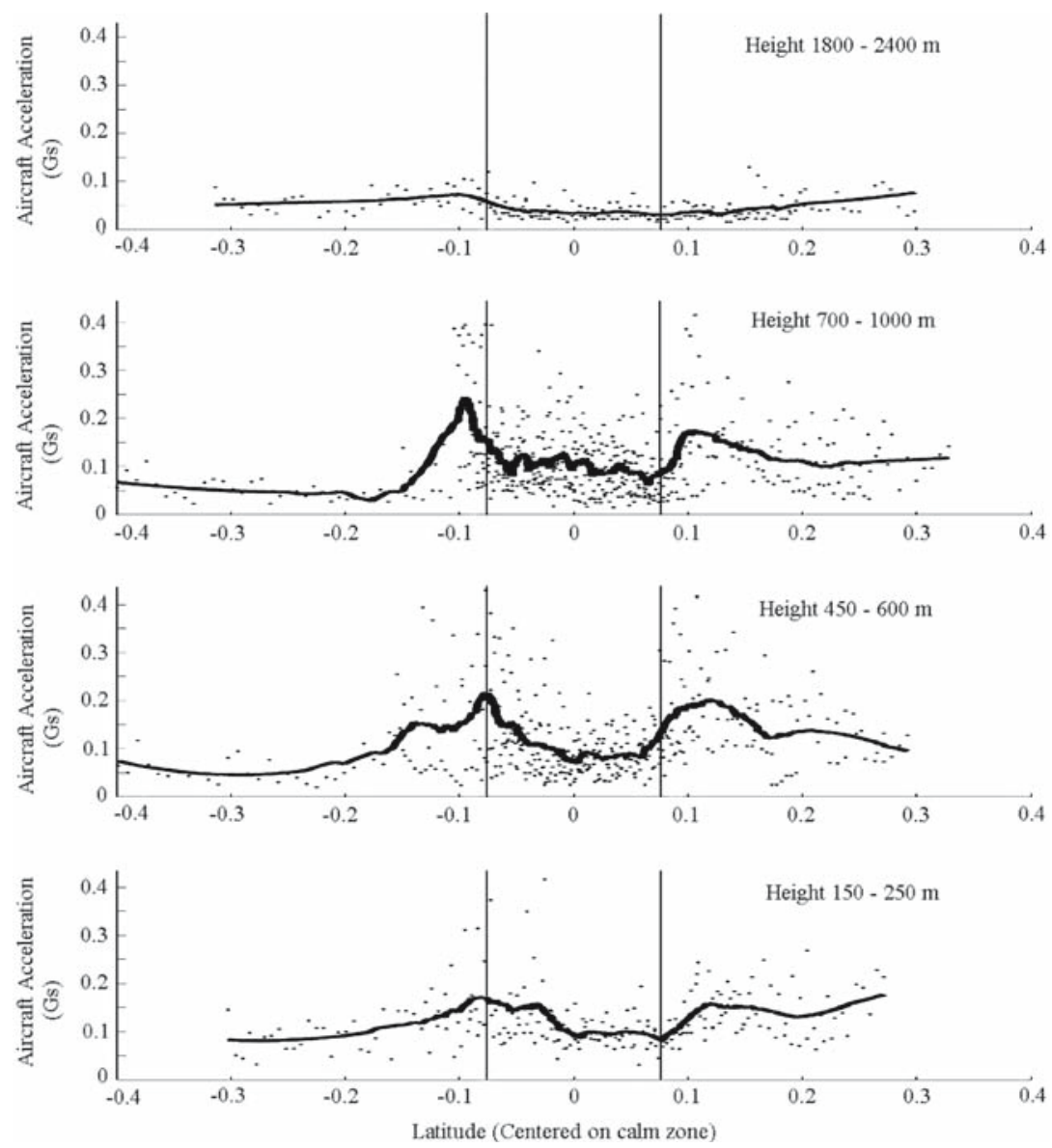

Fig. 12 Composite maximum aircraft acceleration north and south of the calm zone for aircraft heights from $150-250 \mathrm{~m}, 450-600 \mathrm{~m}, 700-1000 \mathrm{~m}$, and $1800-2400 \mathrm{~m}$

Figures 14 shows the composite wind fields from Flights 2, 3, and 4. The legs from Flight 6 were too short to be used here. As with Figs. 12 and 13, the position of each measurement is shown as a distance from the centre point between the northern and southern shear lines and normalized to the average calm zone width. The average locations of the southern and northern surface shear lines are also shown.

The composite winds show that the lightest winds are found in the calm zone located in the lee of the islands and between the northern and southern shear lines. Confirming the accuracy of the aircraft derived wind measurements, the lowest level aircraft derived winds show a strong change in wind speed directly over the region where the pilots observed the surface shear line. North of the calm zone wind speeds are $7-9 \mathrm{~m} \mathrm{~s}^{-1}$ from $085^{\circ}$ while south of the island they increase slightly (9-10 $\left.\mathrm{m} \mathrm{s}^{-1}\right)$ and are from $120^{\circ}$. Within the calm zone the winds are below $4 \mathrm{~m} \mathrm{~s}^{-1}$ and have a southerly direction. While the composite winds within the calm zone were southerly, the winds for individual flights varied in direction. 


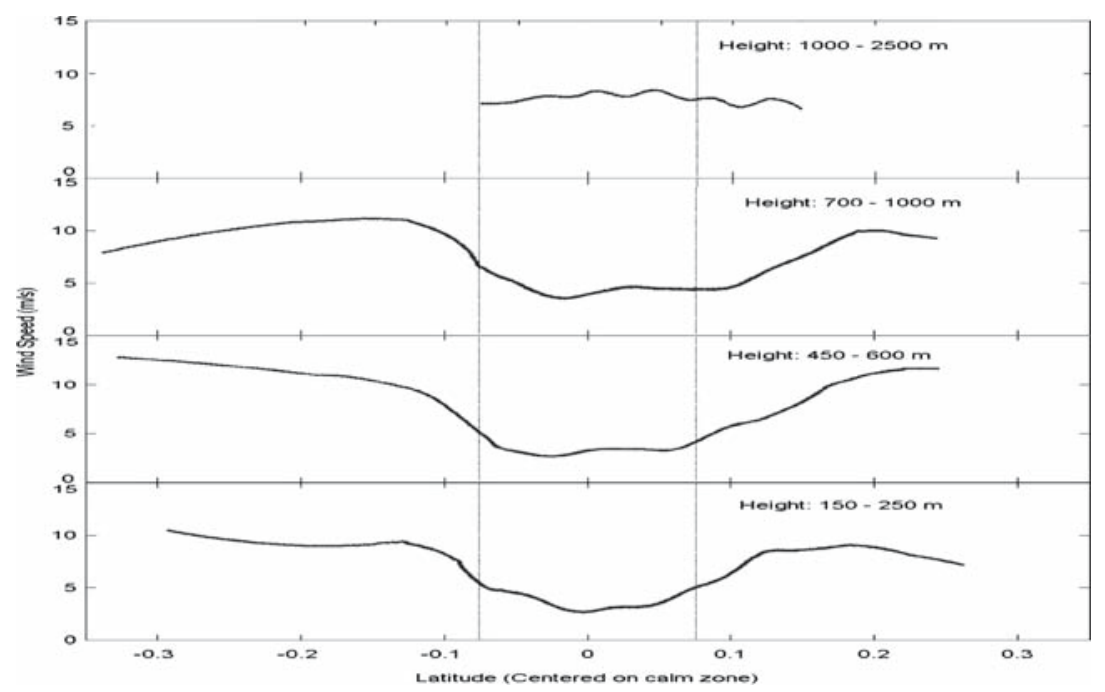

Fig. 13 Composite wind speed obtained from aircraft measurements plotted as a distance from the centre of the calm zone. The location of the southern and northern surface wind shear area (as observed by the pilots) is shown as two lines

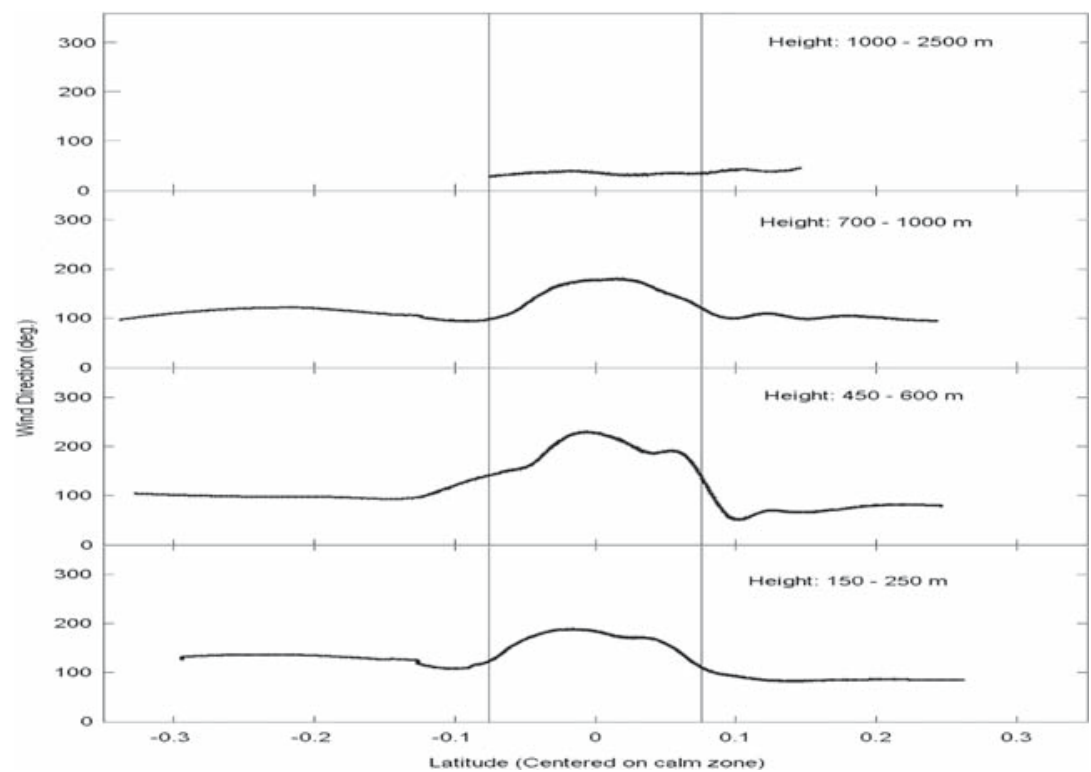

Fig. 14 Composite wind direction obtained from aircraft measurements plotted as a distance from the centre of the calm zone. The location of the southern and northern surface wind shear area (as observed by the pilots) is shown as two lines

At higher altitudes $(450-600 \mathrm{~m})$ the winds increase to $12-13 \mathrm{~m} \mathrm{~s}^{-1}$ north and south of the island. At this height the winds south of the island are more easterly similar to the winds north of the island. Within the calm zone the winds were at or below $4 \mathrm{~m} \mathrm{~s}^{-1}$ and became more westerly in the composite (individual flights had variable 
directions). It can also be noticed that at this altitude the region of largest wind shear has shifted northward, which is consistent with the MM5 model results and turbulence measurements discussed above. Along the southern shear line, the wind shear region remains over the surface shear line suggesting no tilt with height. This is also consistent with model and turbulence measurements discussed above. Similar features can be seen for the 700-1000 m altitudes as well. At the highest level (1800-2400 m) the winds were generally unaffected by the Kauai shadow and showed no decrease in wind speed over the surface calm zone.

\section{Discussion and conclusion}

On 26 June 2003, the Helios aircraft broke apart at 1036 local time off the leeward west coast of Kauai in what appeared to be a typical trade wind day. In order to understand the meteorological conditions on this day MODIS satellite images, modelling studies using the MM5 model at 1-km resolution, and in-situ aircraft measurements were investigated. Both the model results and the satellite image (obtained an hour after the mishap) show a calm region in the lee of the island, surrounded by stronger trade winds. Surrounding the calm zone in the shadow of Kauai are wind shear regions north, south, and above the calm zone where the winds are in transition to background trade wind conditions. Based on the model results, the southern shear line (SSL) has no vertical tilt while the northern shear line (NSL) tilts northward with height and appears to split into two distinct areas. The wind structure with $2-\mathrm{km}$ resolution was compared with that of the $1-\mathrm{km}$ control run, with some significant variations. Since MM5 cannot operate at sub-kilometre resolution, other smaller-scale models must be applied to resolve finer scale circulations.

Although wind shear turbulence was the likely cause of the Helios mishap, several other factors could not be ruled out. Processed MODIS satellite images showed a westward gradient in integrated water vapour as well as isolated patches of larger values. The larger column water vapour amounts may have led to isolate convection enhancing turbulence. Using Lagrangian flow analysis, it was determined that this gradient was associated with differential subsidence following parcel back trajectories. Furthermore, gravity waves, due to island blocking and distant frontal activity, may have been present but could not be confirmed with the existing observations.

In order to gain a better understanding of the Kauai leeside processes, a rapid response aircraft measurement campaign was carried out. Composites of the aircraft measurements (for flights $2,3,4,6$ ) showed the regions of maximum turbulencerelated aircraft accelerations occurred nearly directly over the surface shear line for altitudes up to $1000 \mathrm{~m}$ with the exception that enhanced turbulence was also observed north of the NSL. South of the SSL very little turbulence was experienced. This is consistent with the model results, which showed the SSL had no vertical tilt while the NSL tilted northward with height. At higher elevations (1800-2400 m) turbulence values were greatly reduced. Aircraft derived composite wind speeds were similar to the modelled winds with the southern wind shear region having no vertical tilt while the northern shear region tilted northward with height.

Based on pilot observations, the average width of the surface calm zone was $16.9 \mathrm{~km}$ while the models gave $17.5 \mathrm{~km}$. The aircraft accelerations only rarely exceeded $0.3 \mathrm{~g}$ on the Piper Navaho aircraft and these occurred over the surface shear line at altitudes from 400 to $1000 \mathrm{~m}$. The turbulence over the calm zone was not negligible and 
was found to be larger at the $1000 \mathrm{~m}$ level than at any other height in agreement with the increased shear seen on the model at that height. The flights carried out here provided only limited data sets and further flights are needed in order to obtain a more complete picture of the semi-random turbulent features.

Acknowledgements This research was funded by NASA contract CC-91760B as part of the Helios mishap investigation.

\section{References}

Cox C, Munk W (1955) Some problems in optical oceanography. J Mar Res 14:63-78

Donahue C (2003) Helios data memo: discussion of meteorological conditions during Helios Flight H03-2, AV50780-769, available at NASA Center for AeroSpace Information (CASI), 1-9

Draxler RR, Hess GD (1998) An overview of the Hysplit_4 modeling system for trajectories, dispersion, and deposition. Aust Meteorol Mag 47:295-308

Fritts D, Nastrom G (1992) Sources of mesoscale variability of gravity waves. Part II Frontal, convective, and jet stream excitation. J Atmos Sci 49:111-127

Hafner J, Xie S (2003) Far-field simulations of the Hawaiian Wake: sea surface temperature and orographic effects. J Atmos Sci 60:3021-3032

Hane CE, Ziegler CL (1993) Investigation of the dryline and convective storms initiated along the dryline: field experiments during COPS-91. Bull Amer Meteorol Soc 74:2133-2145

Motell C, Porter JN, Foster J, Bevis M, Businger S (2002) Comparisons of water vapour derived from GPS, sounding and the split window technique. Int J Remote Sensing 23:2335-2339

Noll TE, Brown JM, Perez-Davis ME, Ishmael SD, Tiffany GC, Gaier M (2004) Investigations of the Helios prototype aircraft mishap. Report available at http://www.nasa.gov/pdf/64317main_helios.pdf

Porter JN, Sharma SK, Lienert BR, Lau E, Horton K (2003) Vertical and horizontal aerosol scattering fields over bellows beach, Oahu during the SEAS experiment. J Atmos Oceanic Technol 20:13751387

Ramage CS, Schroeder TA (1999) Trade wind rainfall atop mount Waialeale, Kauai. Mon Wea Rev 127:2217-2226

Rogers RR, Ecklund WL, Carter DA, Gage KS, Ethier SA (1993) Research applications of a boundary-layer wind profiler. Bull Amer Meteorol Soc 74:567-580

Sadler JC (1967) The tropical upper tropospheric trough as a secondary source of typhoons and a primary source of trade-wind disturbance. Hawaii Institute of Geophysics, University of Hawaii, HIG-67-12 and AFCRL-67-0203, 44 pp

Sadler JC (1975) The upper tropospheric circulation over the global tropics. Department of Meteorology, University of Hawaii, UHMET-75-05, 35 pp

Sadler JC, Lander MA, Hori AM, Oda LK (1987) Tropical marine climatic atlas. vol. 2. Meteorology Department, Univer sity of Hawaii, UHMET, $87 \mathrm{pp}$

Smith RB, Gleason AC, Gluhosky PA, Grubisic V (1997) The wake of St. Vincint. J Atmos Sci 54:606-623

Smith RB, Grubisic V (1993) Aerial observations of Hawaii's wake. J Atmos Sci 50:3728-3750

Smolarkiewicz P, Rotunno R (1989) Low froude number flow past three-dimensional obstacles. Part I: Baroclinically generated lee vorticies. J Atmos Sci 46:1154-1164

Smolarkiewicz P, Rotunno R (1990) Low froude number flow past three-dimensional obstacles. Part I: Upwind flow reversal zone. J Atmos Sci 46:1498-1511

Teets EH Jr, Salazar N (1999) Wind and mountain wave observations for the Pathfinder Hawaii flight test operation. NASA/CR-1999-206571

Yang Y, Chen Y (2003) Circulations and rainfall on the lee side of the Island of Hawaii during HaRP. Mon Wea Rev 131:2525-2542 